\title{
New hybrids from peanut (Arachis hypogaea L.) and synthetic amphidiploid crosses show promise in increasing pest and disease tolerance
}

\author{
A.P. Fávero', J.G. Pádua², T.S. Costa², M.A. Gimenes², I.J. Godoy ${ }^{3}$, \\ M.C. Moretzsohn ${ }^{2}$ and M.D. Michelotto ${ }^{4}$ \\ ${ }^{1}$ Embrapa Pecuária Sudeste, São Carlos, SP, Brasil \\ ${ }^{2}$ Embrapa Recursos Genéticos e Biotecnologia, Brasília, DF, Brasil \\ ${ }^{3}$ Instituto Agronomico de Campinas, Campinas, SP, Brasil \\ ${ }^{4}$ Agência Paulista de Tecnologia para os Agronegócios, Pólo Regional Centro-Norte, \\ Pindorama, SP, Brasil \\ Corresponding author: A.P. Fávero \\ E-mail: alessandra.favero@embrapa.br
}

Genet. Mol. Res. 14 (4): 16694-16703 (2015)

Received June 26, 2015

Accepted October 16, 2015

Published December 11, 2015

DOI http://dx.doi.org/10.4238/2015.December.11.17

ABSTRACT. The primary gene pool of the cultivated peanut (Arachis hypogaea L., allotetraploid $\mathrm{AABB}$ ) is very narrow for some important characteristics, such as resistance to pests and diseases. However, the Arachis wild diploid species, particularly those from the section Arachis, still have these characteristics. To improve peanut crops, genes from the wild species can be introgressed by backcrossing the hybrids with $A$. hypogaea. When diploid species whose genomes are similar to those of the cultivated peanut are crossed, sterile hybrids result. Artificially doubling the number of chromosomes of these hybrids results in fertile synthetic polyploids. The objectives of this study were: 1) to obtain progenies by crossing amphidiploids with the cultivated peanut, and 2) to characterize these two groups of materials (amphidiploids and progenies) so that they 
may be efficiently conserved and used. Using morphological, molecular, and pollen viability descriptors we evaluated one cultivar of $A$. hypogaea (IAC 503), eight synthetic amphidiploids, and the progenies resulting from four distinct combinations of crossing between IAC 503 and four amphidiploids.

Key words: Interspecific hybrid; Germplasm; Characterization; Pollen viability; Groundnut; Wild species

\section{INTRODUCTION}

Arachis hypogaea L., the cultivated peanut, is directly consumed and used to produce edible oil, ranking fifth in vegetable oil production in the world (FAOSTAT, 2010). The cultivated groundnut is an allotetraploid (genome formula AABB). This species originated from a cross between two genome diploid species (one A species and one B species), followed by a spontaneous duplication of chromosomes. Molecular (Kochert et al., 1991, 1996; Krapovickas and Gregory, 1994), cytogenetic (Seijo et al., 2004), and crossability and hybrid fertility (Fávero et al., 2006) data all suggest that $A$. duranensis Krapov. \& W.C. Gregory donates the A genome and $A$. ipaënsis Krapov. \& W.C. Gregory donates the B genome to the cultivated peanut (both belong to the section Arachis, one of the nine sections of the genus Arachis (Krapovickas and Gregory, 1994)).

Section Arachis comprises two allotetraploid (A. hypogaea and A. monticola Krapov. \& Rigoni) and 29 diploid species (Krapovickas and Gregory, 1994; Valls and Simpson, 2005). The genomes of section Arachis species were classified for many years as A, B, and D. Recently, analyses of heterochromatic bands and $45 \mathrm{~S}$ rDNA loci patterns led the species previously classified as $\mathrm{B}$ genomes to be arranged into three groups: B, comprising A. ipaënsis, A. magna Krapov., W.C. Gregory \& C.E. Simpson, A. gregoryi C.E. Simpson, Krapov. \& Valls, A. valida Krapov. \& W.C. Gregory, and A. williamsii Krapov. \& W.C. Gregory; K, comprising A. batizocoi Krapov. \& W.C. Gregory, A. cruziana Krapov., W.C. Gregory \& C.E. Simpson, and A. krapovickasii C.E. Simpson, D.E. Williams, Valls \& I.G. Vargas; and F, comprising A. benensis Krapov., W.C. Gregory \& C.E. Simpson and A. trinitensis Krapov. \& W.C. Gregory (Robledo and Seijo, 2010). This new classification is supported by systematic molecular studies on the genus Arachis (Bechara et al., 2010; Friend et al., 2010; Wang et al., 2010).

Species of section Arachis are highly resistant to many pests and diseases that affect A. hypogaea (Company et al., 1982; Gardner and Stalker, 1983; Subrahmanyam et al., 1983; Pande and Rao, 2001; Fávero et al., 2009). Because section Arachis comprises species that have genomes similar to the A or B genomes of the cultivated peanut, the genes involved in the expression of resistance in the wild species can be introgressed into the cultivated peanut by hybridization. Gene introgression can be conducted by crossing the cultivated species with a diploid species, which results in sterile triploid plants. These hybrids are treated with colchicine to duplicate their chromosomes, and allowed to self-pollinate until they reach the tetraploid level, when they develop four sets of chromosomes. In their analysis of a population that Smart and Gregory (1967) obtained from a cross between A. cardenasii Krapov. \& W.C. Gregory and A. hypogaea, Garcia et al. (1995) reported that gene introgression happened through recombination and chromosome substitution. Alternatively, introgression can be performed by obtaining synthetic allopolyploids from crosses between $A$ and $B$ genome species, then duplicating the chromosomes of the hybrids using colchicine (Simpson, 1991). In contrast to the first approach, the latter allows introgression in both genomes at the same time. Consequently, some research groups are developing interspecific 
hybrids of Arachis to introgress wild species genes into A. hypogaea (Burow et al., 2001; Fávero et al., 2006; Kumari et al., 2014).

It is important to characterize synthetic hybrids so they can be effectively used and managed. For example, this characterization allows the hybrids themselves to be identified, and therefore distinguished from autogamous plants, which is an essential step in Arachis because most of its species are autogamous. It can also help prevent misclassification and the loss of genetic integrity during long-term conservation. Finally, it allows the identification of hybrids with several interesting traits to be used in the subsequent steps of the introgression program.

Different types of molecular markers can be used to identify hybrids. In this study, we used microsatellites because they are codominant, multi-allelic, polymorphic, and transferable markers. The objectives of this study were to obtain progenies resulting from crossings between amphidiploids resistant to leaf diseases (late and early leaf spot and rust) and the cultivated peanut, and to characterize these two groups of materials for their efficient conservation and use.

\section{MATERIAL AND METHODS}

\section{Material}

The morphological characterization was performed in seven synthetic amphidiploids (An 4, An 7, An 8, An 9, An 10, An 11, and Di 07T) (Table 1). Four synthetic amphidiploids (An 9, An 10, An 11, and Di 07T) and the cultivar IAC 503 from A. hypogaea were also used in hybridizations, and their progenies were characterized using microsatellite markers so hybrids could be identified. After hybrids were identified, progenies were characterized morphologically and for pollen viability.

\begin{tabular}{|c|c|c|}
\hline Code & Genotype & Genome* \\
\hline cv. IAC 503 & A. hypogaea & AABB \\
\hline An 4 & (A. ipaënsis $\mathrm{K} 30076 \times$ A. duranensis V 14167) $)^{4 \mathrm{x}}$ & BBAA \\
\hline An 7 & (A. vallsii Krapov. \& W.C. Gregory V 7635 x A. williamsii Wi1118) ${ }^{4 \times}$ & $\mathrm{nnBB}$ \\
\hline An 8 & (A. magna V $13751 \times$ A. cardenasii GKP 10017) ${ }^{4 x}$ & BBAA \\
\hline An 9 & $\left(\right.$ A. gregoryi V $6389 \times$ A. stenosperma Krapov. \& W. C. Gregory V 12488) ${ }^{4 x}$ & BBAA \\
\hline An 10 & (A. magna KG $30097 \times$ A. stenosperma $V 15076)^{4 x}$ & BBAA \\
\hline An 11 & (A. vallsii V $7635 \times$ A. stenosperma $V 10229)^{4 \times}$ & nnAA \\
\hline Di 07T & $\left(\right.$ A. batizocoi K 9484 x A. helodes Martius ex Krapov \& Rigoni V6325) ${ }^{4 x}$ & KKAA \\
\hline
\end{tabular}

${ }^{*} \mathrm{nn}$ indicates not yet identified.

\section{Methods}

\section{Hybridization}

Hybrids were created using amphidiploids as male parents and the Arachis hypogaea L. cultivar IAC 503 as the female parent (Table 2). The hybridization consisted of emasculating the flowers of the female parent during the bud phase. The following morning, emasculated flowers were pollinated with fresh pollen from the male parent. 


Table 2. Hybridization outcomes.
\begin{tabular}{lcccr}
\hline Cross (male x female) & No. of pollinations & No. of hybrids identified & Percentage of success & No. of F2 seeds \\
\hline IAC503 $\times$ An 9 & 115 & 2 & 1.74 & 0 \\
IAC503 An 10 & 129 & 12 & 9.30 & 43.92 \\
IAC503 An 11 & 65 & 11 & 44.19 & 34 \\
IAC503 x Di 07T & 86 & 38 & & 10 \\
Total & 395 & $63 / 138$ & & \\
\hline
\end{tabular}

\section{Molecular characterization}

A total of 32 microsatellite loci were screened for polymorphisms using the five parents, which included the four amphidiploids and the A. hypogaea cultivar IAC 503. Each reaction contained $3 \mu \mathrm{L}$ DNA $(2.5 \mathrm{ng} / \mu \mathrm{L}), 4 \mu \mathrm{L}$ primer pairs $(1 \mu \mathrm{M}), 1.3 \mu \mathrm{L}$ 10X polymerase chain reaction (PCR) buffer, $0.6 \mu \mathrm{L} \mathrm{MgCl}, 1.3 \mu \mathrm{L}$ bovine serum albumin $(2.5 \mathrm{mg} / \mathrm{mL}), 1.3 \mu \mathrm{L}$ dNTPs $(2.5 \mathrm{mM})$, $0.25 \mu \mathrm{L}$ Taq DNA polymerase ( $5 \mathrm{U} / \mathrm{\mu L}$ ), and $1.25 \mu \mathrm{L}$ water. The cycling conditions were as follows: 5 min at $94^{\circ} \mathrm{C}$, followed by 301 -min denaturation cycles at $94^{\circ} \mathrm{C}, 1 \mathrm{~min}$ of annealing at $56-60^{\circ} \mathrm{C}, 1 \mathrm{~min}$ of extension at $72^{\circ} \mathrm{C}$, and a final $7-$ min extension at $72^{\circ} \mathrm{C}$. Table 3 lists the annealing temperatures of primer pairs for which polymorphisms were detected in at least one pair of parents. The PCR products were electrophoresed on $1.5 \%$ agarose gel at $120 \mathrm{~V}$ for $2 \mathrm{~h}$ and stained with ethidium bromide, and the fragments were viewed under ultraviolet light.

Table 3. Microsatellite polymorphic loci between crossed parents.

\begin{tabular}{|c|c|c|c|}
\hline Locus & Primer $\left(5^{\prime}-3^{\prime}\right)$ & Annealing temperature $\left({ }^{\circ} \mathrm{C}\right)$ & Polymorphic progenitor \\
\hline \multirow[t]{2}{*}{ seq14E10 } & TTGACAAAATAACCTCACTT & 56 & IAC503 x An9 \\
\hline & ACCTAGTGGGACAAGGCTTT & & \\
\hline \multirow[t]{2}{*}{ seq13A7 } & AACTCGCTTGTACCGGCTAA & 58 & IAC503 x An10, IAC503 x An 11 \\
\hline & AATCCGACGCAATGATAAAA & & \\
\hline \multirow[t]{2}{*}{ seq15D2 } & TTTTGGCTACCTTTGCTGCT & 60 & IAC503 x An 9 \\
\hline & TATATTGTCCTGCAAGCCCG & & \\
\hline \multirow[t]{2}{*}{ seq12E3 } & CTCACACCAATCAGTCGACA & 56 & IAC503 x An9, IAC503 x An10 \\
\hline & GACCAAAACAAAATTTGGAA & & \\
\hline \multirow[t]{2}{*}{ seq10C12 } & TTCACTTCCTAACCGAGCTC & 58 & IAC503 x An10, IAC503 x An11, IAC503 x Di07T, \\
\hline & CAAACTTGGGCCAACAGACT & & \\
\hline \multirow[t]{2}{*}{ seq13E6A } & GTCACGTAATTGGATGCACG & 58 & IAC503 x An9, IAC503 x An10 \\
\hline & TGGCAATTTATTGATGCAGG & & \\
\hline
\end{tabular}

\section{Morphological characterization}

The morphological characterization was conducted at Embrapa Genetic Resources and Biotechnology, Brasilia, Distrito Federal, Brazil, using leaf, flower, and plant structure descriptors. We collected four samples of expanded leaves (counting from the apex of the branch), as well as four flower samples from each hybrid plant and progenitors. We used descriptors established in the literature (IBPGR, 1990; Monçato, 1995), with minor modifications.

Descriptors of the main axis and lateral branches included basal and distal leaflet length and width, petiole and petiolule length, length of the free and adnate parts of stipules, stipule width, the presence of trichomes and bristles on the petiole and petiolule, trichomes on the abaxial and adaxial faces of the leaflets (border, center, and midvein), trichomes and bristles on the free and adnate part of stipules (border and center), anthocyanin on the stipule, bristles on the border of the leaflet, and bristles on the free and adnate parts of stipules. The flower descriptors were standard 
length and width, wing length and width, hypanthium length, lower and upper lip length, and flower color. Plant height and the lengths of lateral branches were also measured.

Morphological differences between the 64 descriptors of hybrids and progenitors were analyzed using principal components analysis and Pearson's correlations with SAS software, version 8.2, using PROC COMP and Microsoft Excel.

\section{Pollen viability}

The fertility of interspecific hybrids of Arachis was estimated using pollen staining. Between 8:00 and 9:30 am, four flowers of each hybrid were randomly chosen and collected. Pollen was distributed on slides with a drop of $2 \%$ acetocarmine with glycerin, after which a coverslip was placed on the sample and slight pressure was applied. An optical microscope (Olympus model BH-2) was used to count, in random order, four replications of 100 pollen grains (including viable and non-viable grains) for each sample. Only two hybrids (Di07T and IAC $503 \times$ An 9) were not evaluated because they produced too few flowers. An analysis of variance compared the average fertility of each hybrid and progenitor. Tukey's tests were then used to identify differences between each hybrid and progenitor.

\section{RESULTS AND DISCUSSION}

\section{Hybridization and hybrid identification}

Four different combinations of IAC 503 and four different amphidiploids (An 9, An 10, An, 11, and Di 07T) were studied, for a total of 395 hybridizations (Table 2). Sixty-three progenies were identified as hybrids using molecular markers. Table 2 shows the combinations of progenitors used, the number of pollinations obtained, the number of hybrids identified using single-sequence repeats, the percentage of success (ratio of the number of hybrids to the number of pollinations), and the number of $F_{2}$ seeds. The most prolific hybrid developed was IAC $503 \times$ An 10; although its percentage of success was $9.3 \%$, it produced $437 F_{2}$ seeds. The microsatellite primer pairs used were developed for $A$. hypogaea (Ferguson et al., 2004). The transferability of microsatellite primers was high, as observed in many other studies on Arachis species (Bravo et al., 2006; Hoshino et al., 2006; Moretzsohn et al., 2009; Koppolu et al., 2010).

The polymorphic loci for at least one pair of parents are listed in Table 3. Polymorphisms between $A$. hypogaea (first three lanes) and several other parents can be seen in Figure 1.

The pair of parents with the largest number of polymorphic loci (five) was IAC 503 and An 8 (A. magna $\times$ A. cardenasii) ${ }^{4 x}$, and the pair with the least (one polymorphic locus) was IAC 503 and Di07T (A. batizocoi x A. helodes) ${ }^{4 x}$. Several authors have shown $A$. magna to be very similar to $A$. ipaënsis (Krapovickas and Gregory, 1994; Milla et al., 2005; Moretzsohn et al., 2009), which is the donor of the B genome to the cultivated peanut (Kochert et al., 1996). A. batizocoi was for many years considered a $\mathrm{B}$ genome, but was recently re-classified as a $\mathrm{K}$ genome species (Robledo and Seijo, 2010). Based on phylogenetic data, $A$. batizocoi is more distantly related to $A$. hypogaea than $A$. magna, while $A$. cardenasii and $A$. helodes, both $A$ genome species, form a monophyletic group (Bechara et al., 2010). Therefore, we expected to observe more polymorphisms between IAC 503 and Di 07T than between IAC 503 and An 8. Our findings of more polymorphisms between IAC 503 and An 8 may be due to high variability in the microsatellite loci.

The variability in the number of hybrids resulting from each cross we evaluated could have several causes, with the most probable being pre-fertilization or post-fertilization barriers. There is 
evidence of pre- and post-zygotic barriers between Arachis species (Tallury et al., 1995); however, to date these barriers have been found in wild diploid species rather than in synthetic polyploids, such as the ones used here.

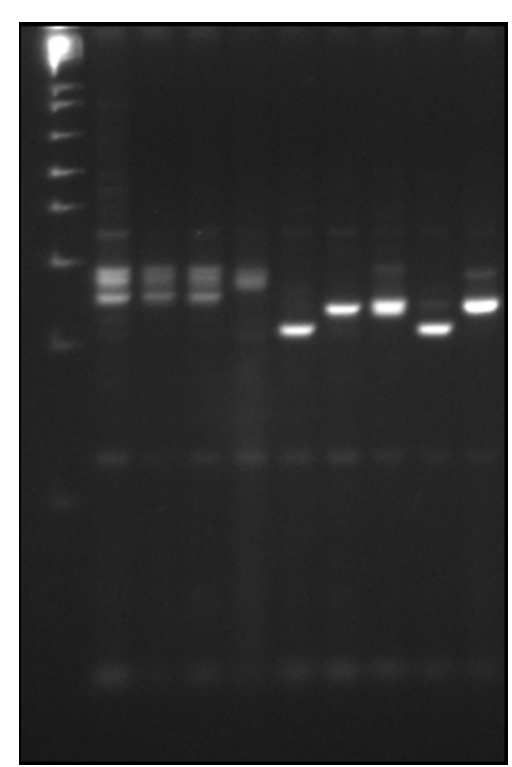

Figure 1. Polymorphisms among Arachis hypogaea (first three lanes) and An 6, An 7, An 8, An 9, An 10, and An 11.

\section{Morphological characterization}

Of the 64 evaluated descriptors, 13 exhibited no morphological variation among hybrids (on either the main axis or lateral branches: trichomes on the border of the abaxial and adaxial sides of the leaflets, trichomes in the center and midvein of the adaxial side of the leaflets, trichomes on the petiole; on the main axis only: trichomes on the petiolule and trichomes on the free part of the stipule, center, and border). Eigen values indicated that the two first components explained $84.76 \%$ of the total variance in morphological characteristics. Nine characteristics emerged as important in genotype discrimination, based on the results of the principal component analysis. The order of contribution to the discrimination of genotypes (and respective values of eigenvectors) was as follows: distal leaflet length on lateral branches (cfdRL: 0,8273); distal leaflet length on the main axis (cfdEC: 0,3311); basal leaflet length on the main axis (cfpEC: 0,3090); distal leaflet width on the main axis (IfdEC: 0,1349 ); petiolule length on lateral branches (cpoRL: 0,1207); distal leaflet width on lateral branches (IfdRL: 0,1168); free part of stipule width on lateral branches (lelRL: -0,1158); free part of stipule length on lateral branches (celRL: 0,1070); and basal leaflet width on the main axis (IfpEC: 0,1047). These results should facilitate future investigations of these genotypes.

Also using principal component analysis, Fávero (2004) used 15 descriptors for the genotype discrimination of wild Arachis species. Six of those were used in the present study (basal and distal leaflet length and width on the main axis, distal leaflet length and width on lateral branches). Pearson's correlation coefficients were calculated for the nine main descriptors (Table 4). These correlations may be due to functional and/or structural proximity between the structures. 
Table 4. Pearson correlation coefficients among the nine main morphological characteristics measured.

\begin{tabular}{|c|c|c|c|c|c|c|c|c|}
\hline & cfpEC & IfpEC & cfdEC & IfdEC & cfdRL & IfdRL & cpoRL & celRL \\
\hline IfpEC & 0.6540 & & & & & & & \\
\hline cfdEC & 0.9827 & 0.7179 & & & & & & \\
\hline IfdEC & 0.6082 & 0.9795 & 0.6894 & & & & & \\
\hline cfdRL & 0.6422 & 0.5481 & 0.6897 & 0.5360 & & & & \\
\hline IfdRL & 0.8164 & 0.3596 & 0.7961 & 0.3024 & 0.4049 & & & \\
\hline cpoRL & 0.7829 & 0.3842 & 0.7509 & 0.2890 & 0.3619 & 0.9713 & & \\
\hline celRL & 0.4806 & 0.7600 & 0.5470 & 0.7432 & 0.4821 & 0.3060 & 0.3665 & \\
\hline leIRL & -0.2471 & -0.4237 & -0.2978 & -0.5135 & -0.4737 & 0.1772 & 0.2909 & -0.0451 \\
\hline
\end{tabular}

cfpEC, basal leaflet length on the main axis; IfpEC, basal leaflet width on the main axis; cfdEC, distal leaflet length on the main axis; IfdEC, distal leaflet width on the main axis; cfdRL, distal leaflet length on the lateral branch; IfdRL, distal leaflet width on the lateral branch; $c p o R L$, petiolule length on the lateral branch; celRL, free part of stipule length on the lateral branch; leIRL, free part of stipule width on the lateral branch. Italicized values indicate significant correlations at $P<0.05$.

A biplot graph was obtained (Figure 2) by multiplying the values of the main characteristics observed in Components 1 and 2 by the average values of each characteristic for each genotype. The hybrid IAC $503 \times$ An10 was closer to the progenitor An10 than to the progenitor IAC 503, and the hybrid IAC $503 \times$ An11 was closer to An11 than to IAC 503. The amphidiploids An7, An8, An9, An10, and An11 exhibited many morphological similarities. Consequently, all of the hybrids were closer to the wild progenitors than to A. hypogaea cv IAC 503, except for hybrid IAC $503 \times$ An9, which was morphologically more similar to IAC 503.

Table 5 shows the average sizes of the nine main characteristics measured. These data are congruent with each plant's growth habit; for example, all of the hybrids were prostrate, as were the wild progenitors, whereas the hybrid IAC $503 \times$ An 9 had a bunching habit, similar to some varieties of $A$. hypogaea. Data for the progenitor Di 07T were not evaluated because the plant was not in good enough condition for morphological characterization and pollen viability observations. However, we expect results for this hybrid to be similar to those of the other amphidiploids.

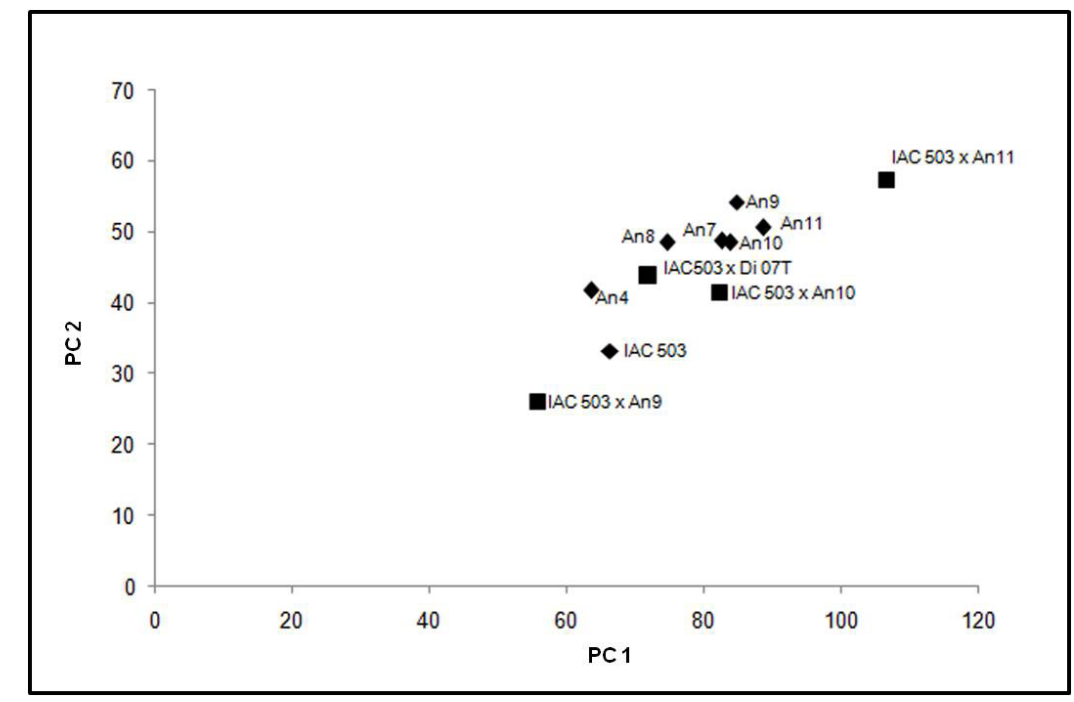

Figure 2. Biplot graph based on a principal component analysis of the nine main descriptors for PC 1 (x-axis) and PC 2 (y-axis). Diamonds indicate the progenitors and squares indicate the interspecific hybrids. 
Table 5. Average size $(\mathrm{mm})$ of the nine main characteristics for each evaluated genotype of Arachis.

\begin{tabular}{|c|c|c|c|c|c|c|c|c|c|}
\hline Genotype & cfpEC & IfpEC & cfdEC & IfdEC & $\operatorname{cfdRL}$ & IfdRL & cpoRL & celRL & lelRL \\
\hline IAC 503 & 38.23 & 15.24 & 43.87 & 18.53 & 36.67 & 19.02 & 11.11 & 21.28 & 3.15 \\
\hline IAC $503 \times$ An 9 & 28.22 & 13.30 & 36.38 & 16.63 & 32.22 & 17.03 & 9.53 & 18.35 & 2.73 \\
\hline An 9 & 57.30 & 26.72 & 67.65 & 34.57 & 38.46 & 26.80 & 9.72 & 14.16 & 4.84 \\
\hline IAC 503 & 38.23 & 15.24 & 43.87 & 18.53 & 36.67 & 19.02 & 11.11 & 21.28 & 3.15 \\
\hline IAC 503 x An 10 & 47.35 & 19.88 & 53.53 & 23.67 & 45.91 & 26.53 & 13.37 & 22.78 & 3.63 \\
\hline An 10 & 55.95 & 24.55 & 61.30 & 29.74 & 41.06 & 22.90 & 10.14 & 21.42 & 4.61 \\
\hline IAC 503 & 38.23 & 15.24 & 43.87 & 18.53 & 36.67 & 19.02 & 11.11 & 21.28 & 3.15 \\
\hline IAC 503 x An 11 & 68.49 & 26.85 & 76.01 & 32.41 & 55.64 & 30.51 & 11.79 & 24.35 & 4.78 \\
\hline An 11 & 59.46 & 18.91 & 68.83 & 23.68 & 44.14 & 23.81 & 9.01 & 21.40 & 4.28 \\
\hline IAC 503 & 38.23 & 15.24 & 43.87 & 18.53 & 36.67 & 19.02 & 11.11 & 21.28 & 3.15 \\
\hline IAC $503 \times$ Di 07T & 43.81 & 19.05 & 50.66 & 23.21 & 35.68 & 29.83 & 12.93 & 20.33 & 3.16 \\
\hline An 4 & 40.98 & 20.64 & 47.40 & 25.06 & 29.14 & 23.94 & 10.85 & 17.54 & 4.47 \\
\hline An 7 & 58.45 & 17.97 & 62.65 & 23.77 & 40.28 & 21.78 & 9.04 & 21.10 & 4.53 \\
\hline An 8 & 45.25 & 26.15 & 56.49 & 35.66 & 34.27 & 30.76 & 11.23 & 14.60 & 4.71 \\
\hline
\end{tabular}

cfpEC, basal leaflet length on the main axis; IfpEC, basal leaflet width on the main axis; cfdEC, distal leaflet length on the main axis; IfdEC, distal leaflet width on the main axis; cfdRL, distal leaflet length on the lateral branch; IfdRL, distal leaflet width on the lateral branch; cpoRL, petiolule length on the lateral branch; celRL, free part of stipule length on the lateral branch; leIRL, free part of stipule width on the lateral branch.

\section{Pollen viability}

The percentages of pollen viability for the cultivar of $A$. hypogaea, the amphidiploids, and of the three $\mathrm{F}_{1}$ hybrids are listed in Table 6 . The IAC $503 \times$ An 9 plants were not evaluated for pollen viability because they did not produce enough flowers. A. hypogaea and the amphidiploids exhibited the highest percentages of viable pollen, ranging from 84.00 to $88.67 \%$. Only one hybrid did not differ from the group cited above, IAC $503 \times$ An 10. These data corroborate our findings that $F_{1}$ plants produced 437 seeds (shown in Table 2). The other two interspecific hybrids had the lowest percentages of pollen viability $(65.50 \%$ for IAC $503 \times$ An 11 and $53.75 \%$ for IAC $503 \times$ Di 07T). However, they were fertilized and produced a few seeds (Table 2).

\begin{tabular}{lc}
\multicolumn{2}{c}{ Table 6. Average percentage of pollen viability of Arachis interspecific hybrids. } \\
\hline Genotype & Pollen viability (\%) \\
\hline IAC 503 & $88.67^{\mathrm{a}}$ \\
An 7 & $88.50^{\mathrm{a}}$ \\
An 10 & $86.00^{\mathrm{a}}$ \\
An 4 & $84.50^{\mathrm{a}}$ \\
An 8 & $84.25^{\mathrm{a}}$ \\
An 11 & $84.25^{\mathrm{a}}$ \\
An 9 & $84.00^{\mathrm{a}}$ \\
IAC $503 \times$ An 10 & $71.75^{\mathrm{ab}}$ \\
IAC $503 \times$ An 11 & $65.50^{\mathrm{b}}$ \\
IAC $503 \times$ Di 07 T & $53.75^{\mathrm{b}}$ \\
\hline
\end{tabular}

Genotypes with the same superscript letters were not significantly different from each other at $\mathrm{P}<0.05$.

\section{CONCLUSIONS}

The cultivated peanut has a narrow gene pool in terms of pest and disease resistance. We obtained synthetic amphidiploids for the purpose of introgression into the cultivated peanut, which may eventually improve its pest and disease resistance. The results demonstrate that it is possible to produce new $F_{1}$ interspecific hybrids besides those documented to date. The 
morphological characterization of our new hybrids revealed that most were more similar to the amphidiploid progenitors than to the $A$. hypogaea progenitor, except for the IAC $503 \times$ An 9 hybrid. The most prolific combination achieved was IAC 503 x An 10, the amphidiploids produced by the hybridization and polyploidization of $A$. magna KG 30097 and A. stenosperma $\mathrm{V} 15076$. This interesting germplasm should continue to be studied in order to develop new breeding lines.

\section{Conflicts of interest}

The authors declare no conflicts of interest.

\section{ACKNOWLEDGMENTS}

The authors thank Embrapa and CNPq for financial support.

\section{REFERENCES}

Bechara MD, Moretzsohn MC, Palmieri DA, Monteiro JP, et al. (2010). Phylogenetic relationships in genus Arachis based on ITS and 5.8S rDNA sequences. BMC Plant Biol. 10: 255.

Bravo JP, Hoshino AA, Angelici CMLCD, Lopes CR, et al. (2006). Transferability and use of microsatellite markers for the genetic analysis of the germplasm of some Arachis section species of the genus Arachis. Genet. Mol. Biol. 29: 516-524.

Burow MD, Simpson CE, Starr JL and Paterson AH (2001). Transmission genetics of chromatin from a synthetic amphidiploid to cultivated peanut (Arachis hypogaea L.): broadening the gene pool of a monophyletic polyploidy species. Genetics 159: 823-37.

Company M, Stalker HT and Wynne JC (1982). Cytology and leafspot resistance in A. hypogaea x wild species hybrids. Euphytica 31: 885-893.

FAOSTAT- Food and Agriculture Organization of the United Nations (2010). Available at [http://faostat.fao.org/]. Accessed February 27, 2012.

Fávero AP (2004). Cruzamento entre espécies silvestres de Arachis visando à introgressão de genes de resistência a doenças no amendoim cultivado. Thesis, Escola Superior de Agricultura Luiz de Queiroz, Universidade de São Paulo, Piracicaba.

Fávero AP, Simpson CE, Valls FMJ and Velho NA (2006). Study of evolution of cultivated peanut trough crossability studies among Arachis ipaënsis, A duranensis and A. hypogaea. Crop Sci. 46: 1546-1552.

Fávero AP, Moraes SAM, Garcia AAF, Valls JFM, et al. (2009). Characterization of rust, early and late leaf spot resistance in wild and cultivated peanut germplasm. Sci. Agr. 66: 110-117.

Ferguson ME, Burow MD, Schulze SR, Bramel PJ, et al. (2004). Microsatellite identification and characterization in peanut ( $A$. hypogaea L.). Theor. Appl. Genet. 108: 1064-1070.

Friend SA, Quandt D, Tallury SP, Stalker HT, et al. (2010). Species, genomes, and section relationships in the genus Arachis (Fabaceae): a molecular phylogeny. Plant Syst. Evol. 290: 185-199.

Garcia GM, Stalker HT and Kochert G (1995). Introgression analysis of an interspecific hybrid population in peanuts (Arachis hypogaea L.) using RFLP and RAPD markers. Genome 38: 166-176.

Gardner MEB and Stalker HT (1983). Cytology and leafspot resistance of Section Arachis amphidiploids and their hybrids with A. hypogaea. Crop Sci. 23: 1069-1074.

Hoshino AA, Bravo JP, Angelici CM, Barbosa AVG, et al. (2006). Heterologous microsatellite primer pairs informative for the whole genus Arachis. Genet. Mol. Biol. 29: 665-675.

IBPGR- International Board for Plant Genetic Resources (1990). Preliminary descriptors for Arachis. IBPGR, Rome.

Kochert G, Halward T, Branch WD and Simpson CE (1991). RFLP variability in peanut (Arachis hypogaea L.) cultivars and wild species. Theor. Appl. Genet. 81: 565-570.

Kochert G, Stalker HT, Gimenes MA, Galgaro L, et al. (1996). RFLP and cytogenetic evidence on the origin and evolution of allotetraploid domesticated peanut Arachis hypogaea (Leguminosae). Am. J. Bot. 83: 1282-1291.

Koppolu R, Upadhyaya HD, Dwivedi SL, Hoisington DA, et al. (2010) Genetic relationships among seven sections of genus Arachis. studied by using SSR markers. BMC Plant Biology 10: 15.

Krapovickas A and Gregory WC (1994). Taxonomía del género Arachis (Leguminosae). Bonplandia 8: 1-186.

Kumari V, Gowda MVC, Tasiwal V, Pandey MK, et al. (2014). Diversification of primary gene pool through introgression of 
resistance to foliar diseases from synthetic amphidiploids to cultivated groundnut (Arachis hypogaea L.). Crop J. 2: 110-119.

Milla SR, Isleib TG and Stalker HT (2005). Taxonomic relationships among Arachis sect. Arachis species as revealed by AFLP markers. Genome 48: 1-11.

Monçato L (1995). Caracterização Morfológica de Germoplasma de Espécies de Arachis, secção Caulorrhizae, pela Análise Multivariada. Master's thesis, Universidade Estadual Paulista "Julio de Mesquita Filho".

Moretzsohn MC, Barbosa AVG, Alves-Freitas DMT, Teixeira C, et al. (2009). A linkage map for the B-genome of Arachis (Fabaceae) and its synteny to the A-genome. BMC Plant Biol. 9: 40.

Pande S and Rao JN (2001). Resistance of wild Arachis species to late leaf spot and rust in greenhouse trials. Plant Dis. 85: 851-855.

Robledo G and Seijo G (2010). Species relationships among the wild B genome of Arachis species (section Arachis) based on FISH mapping of rDNA loci and heterochromatin detection: a new proposal for genome arrangement. Theor. Appl. Genet. 121: 1033-1046.

Seijo GJ, Lavia GI, Fernandez A, Krapovickas A, et al. (2004). Physical mapping of the 5 S and 18S-25S rRNA genes by FISH as evidence that Arachis duranensis and $A$. ipaënsis are the wild diploid progenitors of $A$. hypogaea (Leguminosae). Am. J. Bot. 91: 1294-1303.

Smartt J and Gregory WC (1967). Interspecific cross-compatibility between the cultivated peanut Arachis hypogaea L. and other members of the genus Arachis. Oleagineaux 22: 355-364.

Simpson CE (1991). Pathways for introgression of pest resistance into A. hypogaea L. Peanut Sci. 18: 22-26.

Subrahmanyam P, Moss JP and Rao VR (1983). Resistance to peanut rust in wild Arachis species. Plant Dis. 67: $209-212$.

Tallury SP, Stalker HT and Patee HE (1995). Early reproductive ontogeny in interspecific crosses of Arachis hypogaea and Section Arachis species. Ann. Bot. 76: 397-404.

Valls JFM and Simpson CE (2005). New species of Arachis L. (Leguminosae) from Brazil, Paraguay and Bolivia. Bonplandia 14: 35-63.

Wang CT, Wang XZ, Tang YY, Chen DX, et al. (2010). Phylogeny of Arachis based on internal transcribed spacer sequences. Genet. Resour. Crop Evol. 58: 311-319. 